\title{
Contribuição das emendas parlamentares ao orçamento do Sistema Único de Assistência Social ${ }^{1}$
}

\author{
Rodrigo Morais Lima Delgado \\ Ministério do Desenvolvimento Social (MDS) \\ Rodrigo Lino de Brito \\ Agência Nacional de Vigilância Sanitária (Anvisa)
}

Mariana Helcias Côrtes Sagastume

Ministério do Desenvolvimento Social (MDS)

Bruno Pinto Moraes

Tribunal de Contas da União(TCU)

Este artigo buscou identificar a relevância orçamentária e financeira, assim como as consequências das emendas parlamentares ao orçamento do Sistema Único de Assistência Social (Suas). Nesse sentido, identificou-se, no período de 2012 a 2015, o volume de recursos destinados via emenda parlamentar para o orçamento do Suas, mais especificamente para o orçamento da Proteção Social Especial. Por meio das informações disponíveis nos sistemas de monitoramento da execução orçamentária da União, das bases de dados de gestão de convênios do Fundo Nacional de Assistência Social e de entrevistas semiestruturadas com gestores nacionais do Suas, foi realizada uma exploração inicial de como a gestão nacional (Poder Executivo) da política de assistência social vem lidando com os recursos alocados pelo Poder Legislativo no orçamento da União. Foi possível verificar que a consolidação do orçamento impositivo, por meio da Emenda Constitucional no 86/2015, traz importantes desafios para a gestão do Suas na estruturação de uma agenda com o Parlamento, assim como na estruturação de processos organizacionais que deem conta dessa nova realidade.

Palavras-chave: orçamento público, emenda parlamentar, orçamento impositivo, execução orçamentária, política de saúde

\footnotetext{
${ }^{1}$ Os autores agradecem às contribuições dos pareceristas que realizaram a revisão anônima e apresentaram sugestões relevantes para este artigo. Agradecemos também aos colegas da 10ạ Turma da Especialização em Gestão Pública da Enap que enriqueceram o caminho desse texto com reflexões variadas sobre os desafios da administração pública brasileira.
}

[Artigo recebido em 29 de julho de 2016. Aprovado em 6 de julho de 2017.] 


\section{Contribuciones de las enmiendas parlamentarias al presupuesto del Sistema Único de Asistencia Social}

Este artículo ha buscado identificar la relevancia presupuestaria y financiera además de las consecuencias de las enmiendas parlamentarias al presupuesto del Sistema Único de Asistencia Social (Suas). En ese sentido, se ha identificado, en el periodo de 2012 a 2015, el volumen de recursos destinados por medio de enmienda parlamentaria al presupuesto del Suas, más específicamente para el presupuesto de la Protección Social Especial. Por medio de las informaciones disponibles en los sistemas de monitoreo de la ejecución del presupuesto de la Unión Federal, de las bases de datos de gestión de convenios del Fondo Nacional de Asistencia Social y de entrevistas semiestructuradas con gestores nacionales del Suas, se llevó a cabo una exploración inicial como la gestión nacional (Poder Ejecutivo) de la política de asistencia social se ha ocupado de los recursos asignados por la Legislatura en el presupuesto de la Unión. Fue posible verificar que la consolidación del presupuesto impositivo, por medio de la Enmienda Constitucional no 86/2015, trae importantes retos para la gestión del Suas en la estructuración de una agenda con el Parlamento, y en la organización de procesos de negocio que den cuenta de esta nueva realidad.

Palabras clave: presupuesto público, enmienda parlamentaria, presupuesto impositivo, ejecución presupuestaria, política de salud

\section{Contribution of parliamentary amendments to the budget of the Unified Social Assistance System}

This paper aims to identify the budgetary and financial relevance, as well as the consequences, of the parliamentary amendments to the budget of the Unified Social Assistance System (Suas). Therefore, it has identified, in the period from 2012 to 2015, the volume of resources allocated via parliamentary amendments to the SUAS budget, more specifically to the budget of the Special Social Protection. Through the information available in the monitoring systems for the Union's budget implementation, in the data bases for agreements management of the Nation Fund for Social Assistance and in semi-structured interviews with the Suas national managers, an initial exploration of how the national management (Executive Power) of the Social Assistance Policy has been dealing with the resources allocated by the Legislative Power in the budget of the Union.. It was possible to verify that the consolidation of the mandatory budget, via Constitutional Amendment $n$. $86 / 2015$, presents important challenges for the management of Suas in the structuring of an agenda with the parliament, as well as in the organization of processes that take account of this new reality.

Keywords: public budget, parliamentary amendment, tax budget, budget execution, health policy 


\section{Introdução}

A literatura tem apontado que a política de assistência social no Brasil assumiu o caráter de política pública a partir da Constituição Federal de 1988 (CF/88), e que sua regulamentação se deu de forma lenta e gradual, dada a dificuldade de reconhecimento da assistência social como direito, principalmente pela suscetibilidade às manobras políticas que davam um caráter assistencialista e clientelista às suas ações e pela fragmentação de recursos a ela destinados.

Além de criar uma arquitetura sistêmica que reorganizou a relação da União com os demais entes federados por meio de mecanismos de fortalecimento de gestão, da transparência e de pactuação federativa, a regulação do mecanismo de repasse de recursos contínuos e regulares, conforme disposto no artigo 30 da Lei Federal no 8.742/93 (Lei Orgânica de Assistência Social - Loas), com o incentivo e a instituição dos fundos de assistência social nos três níveis da Federação, foi um importante marco para o avanço do financiamento público da política de assistência social.

A construção desse mecanismo de financiamento se constituiu sobre um discurso de profissionalização da política, pois uma maior previsibilidade de recursos redundaria em uma melhor capacidade de planejamento e execução, em contraponto ao modelo de financiamento por meio de convênios que vigeu historicamente.

No entanto, a figura do financiamento via convênio permaneceu ocorrendo, seja para sustentar a realização de ações específicas (como construção de equipamentos públicos), seja em função das emendas parlamentares ao orçamento (que continuam sendo executadas via convênio).

Nesse sentido, nosso trabalho explorou o processo de emendas parlamentares ao orçamento do Sistema Único de Assistência Social (Suas), mais especificamente ao orçamento da Proteção Social Especial, e buscou identificar alguns efeitos desse processo na execução orçamentária e financeira do período de 2012 a 2015.

As mudanças trazidas pela criação do orçamento impositivo (existente a partir da Lei Orçamentária de 2014) no processo de execução orçamentária e financeira do orçamento da assistência social no âmbito da União apontam que o processo de elaboração e execução do orçamento da assistência social no âmbito da União deve, ainda mais, levar em consideração a agenda entre o Poder Executivo e o Poder Legislativo para o alcance dos objetivos definidos no âmbito da política nacional de assistência social.

Para identificarmos os efeitos das emendas parlamentares na gestão federal do orçamento do Suas e das possíveis mudanças desencadeadas pelo orçamento impositivo, buscamos informações nas bases de monitoramento da execução 
orçamentária e financeira da União e nas bases de gestão de convênios do Fundo Nacional de Assistência Social.

Quanto à agenda possível entre o Poder Executivo e o Poder Legislativo federais, por meio de entrevistas semiestruturadas junto aos gestores nacionais da política de assistência social, buscamos identificar as ideias dos referidos entrevistados sobre a relevância, a importância e o papel das emendas parlamentares no orçamento do Suas, assim como a percepção desses gestores sobre a relação entre o Poder Executivo e o Poder Legislativo a partir de emendas parlamentares ao orçamento do Suas.

Nosso trabalho foi uma aproximação ao tema e, nesse sentido, conseguimos identificar um conjunto de questões relacionadas ao aperfeiçoamento administrativo e ao aprofundamento da relação entre o Executivo e o Legislativo, assim como pudemos ter a dimensão do papel das emendas parlamentares no orçamento da Proteção Social Especial no Suas no período analisado.

Podemos concluir que, entre os efeitos colaterais, desejados ou não, da criação do orçamento impositivo, a gestão nacional da política de assistência social reconhece a necessidade de se estreitar o diálogo com o Poder Legislativo no que diz respeito ao processo orçamentário e à implementação do Suas. Dessa forma, com os achados desse artigo, espera-se poder apresentar aos gestores nacionais do Suas informações e análises que subsidiem, a partir da perspectiva do orçamento impositivo, a construção de uma agenda com o Parlamento brasileiro para o fortalecimento da política de assistência social.

\section{Organização do Sistema Único de Assistência Social}

A política de assistência social, juntamente com a política de saúde e a política de previdência social, faz parte do tripé que representa a seguridade social no Brasil, conforme dispõe a Constituição Federal de 1988 (CF/88). No campo orçamentário, a seguridade social está refletida no que se denomina esfera $20^{2}$, que trata de todas as despesas relacionadas a essas políticas, independente do órgão que execute esses recursos (BRASIL, 2013a, p. 11).

A literatura atual aponta que a política de assistência social no Brasil assume o caráter de política pública a partir da CF/88, (BRANDÃo, 2012), (CASTRO, 2012) e

\footnotetext{
${ }^{2} \mathrm{Na}$ Lei Orçamentária Anual da União a esfera 20 tem por finalidade identificar se a despesa pertence ao Orçamento Fiscal, da Seguridade Social ou de Investimento das Empresas Estatais, conforme disposto no § 50 do art. 165 da Constituição Federal. O código 20 abrange todas as entidades e órgãos vinculados ao Orçamento da Seguridade Social, da administração direta ou indireta, bem como os fundos e fundações instituídos e mantidos pelo Poder Público (BRASIL, 2013b).
} 
que sua regulamentação se deu de forma lenta e gradual, pois há uma dificuldade histórica no reconhecimento da assistência social como direito, principalmente pela suscetibilidade às manobras políticas que davam um caráter assistencialista e clientelista às suas ações e pela fragmentação de recursos a ela destinados (BOSCHETTI; TEIXEIRA, 2002).

Esse processo de estruturação como política pública demandou a constituição de um arcabouço jurídico e institucional que se inicia com a organização da assistência social a partir da sanção da Lei Federal no 8.742/93 - conhecida como Lei Orgânica de Assistência Social (Loas) e que deu escopo para a construção, por meio de um relevante processo de participação social e de pactuação federativa, de um sistema público de assistência social conhecido com Sistema Único de Assistência (Suas), cujos principais marcos se encontram no quadro abaixo:

\section{Quadro 1: Principais marcos da política nacional de assistência social}

\begin{tabular}{|c|c|}
\hline 1995 & $\begin{array}{l}\text { Decreto Federal no 1605/1995 regulamenta o Fundo Nacional de Assistência } \\
\text { Social, instituído pela Loas. } \\
\text { I Conferência Nacional de Assistência Social. } \\
\text { Decreto Federal no 1744/1995 regulamenta o Benefício de Prestação } \\
\text { Continuada (BPC), devido à pessoa portadora de deficiência e ao idoso, de } \\
\text { que trata a Loas. }\end{array}$ \\
\hline 1997 & $\begin{array}{l}\text { Resolução do Conselho Nacional de Assistência Social (CNAS) no 204/1997 } \\
\text { aprova a 1a Norma Operacional Básica da Assistência Social. } \\
\text { II Conferência Nacional de Assistência Social. }\end{array}$ \\
\hline 1998 & $\begin{array}{l}\text { Lei no 9.604/1998 determina a prestação de contas da aplicação dos recursos } \\
\text { financeiros oriundos do Fundo Nacional de Assistência Social (FNAS). } \\
\text { Decreto Federal no 2.529/1998 dispõe sobre a transferência de recursos } \\
\text { do FNAS para os fundos estaduais, do Distrito Federal e municipais, e sua } \\
\text { respectiva prestação de contas. } \\
\text { Resolução CNAS no 207/1998 aprova Política Nacional de Assistência Social } \\
\text { (PNAS) e a 2a Norma Operacional Básica da Assistência Social. }\end{array}$ \\
\hline 2001 & $\begin{array}{l}\text { Decreto Federal no 3877/2001 institui o Cadastro Único de Programas } \\
\text { Sociais do Governo Federal (CadÚnico). }\end{array}$ \\
\hline 2003 & $\begin{array}{l}\text { Criação do Ministério da Assistência Social. } \\
\text { IV Conferência Nacional de Assistência Social. Esta conferência delibera pela } \\
\text { criação do Sistema Único de Assistência Social no Brasil. }\end{array}$ \\
\hline
\end{tabular}




\begin{tabular}{|c|c|}
\hline 2004 & $\begin{array}{l}\text { Lei no 10.836/2004 cria o Programa Bolsa Família, regulamentada pelo } \\
\text { Decreto Federal no 5.209/2004. } \\
\text { Resolução CNAS no 145/2004 aprova a Política Nacional de Assistência Social } \\
\text { (PNAS), a qual institui o Sistema Único da Assistência Social. } \\
\text { Criação do Ministério do Desenvolvimento Social e Combate à Fome (MDS). }\end{array}$ \\
\hline 2005 & $\begin{array}{l}\text { Resolução CNAS no 130/2005 aprova a 3a Norma Operacional Básica do } \\
\text { Sistema Único da Assistência Social (NOB/SUAS). Essa norma inova a gestão } \\
\text { financeiro-orçamentária, conferindo maior agilidade e continuidade aos } \\
\text { repasses. } \\
\text { Resolução CNAS no 130/2005 cria a Comissão Intergestores Tripartite do } \\
\text { Suas. } \\
\text { V Conferência Nacional de Assistência Social. Essa conferência aprova o 1o } \\
\text { Plano Decenal do Suas (2005 a 2015). }\end{array}$ \\
\hline 2006 & $\begin{array}{l}\text { Resolução CNAS no } 269 \text { aprova 1a Norma Operacional Básica de Recursos } \\
\text { Humanos do Sistema Único de Assistência Social (NOB-RH/SUAS). }\end{array}$ \\
\hline 2007 & $\begin{array}{l}\text { Decreto Federal no 6.214/2007 regulamenta o Benefício de Prestação } \\
\text { Continuada da Assistência Social (revogando o Decreto Federal no 1744/95). } \\
\text { Portaria no 351/2007dispõe sobre a adesão dos Estados e do Distrito Federal } \\
\text { ao Sistema Único de Assistência Social (Suas). } \\
\text { VI Conferência Nacional de Assistência Social. }\end{array}$ \\
\hline 2009 & $\begin{array}{l}\text { Resolução da Comissão Intergestores Tripartite (CIT) no 07/2009 aprova o } \\
\text { Protocolo de Gestão Integrada de Serviços, Benefícios e Transferências de } \\
\text { Renda no âmbito do Suas. } \\
\text { Resolução CNAS no 109/2009 aprova a Tipificação Nacional de Serviços } \\
\text { Socioassistenciais. } \\
\text { VII Conferência Nacional de Assistência Social. }\end{array}$ \\
\hline 2011 & $\begin{array}{l}\text { Lei no } 12.435 / 2011 \text { altera a Lei } n \text { o } 8.742 / 93 \text { (Loas) incorporando em sua } \\
\text { redação o Sistema Único de Assistência Social. } \\
\text { VIII Conferência Nacional de Assistência Social. }\end{array}$ \\
\hline 2012 & $\begin{array}{l}\text { Resolução CIT no 16/2012 pactua a atual Norma Operacional Básica do } \\
\text { Sistema Único de Assistência Social. } \\
\text { Resolução CNAS no 33/2012 aprova a atual Norma Operacional Básica do } \\
\text { Sistema Único de Assistência Social. Entre outros pontos, a atual NOB institui } \\
\text { os Blocos de Financiamento, que modernizam e flexibilizam a utilização de } \\
\text { recursos do cofinanciamento federal pelos entes. }\end{array}$ \\
\hline 2013 & $\begin{array}{l}\text { Resolução CNAS no 18/2013 dispõe acerca das prioridades e metas } \\
\text { específicas para a gestão municipal do Sistema Único de Assistência Social } \\
\text { (Suas), para o quadriênio 2014-2017. } \\
\text { Resolução CNAS no 32/2013 dispõe sobre o Pacto de Aprimoramento da } \\
\text { Gestão dos Estados e do Distrito Federal no âmbito do Sistema Único de } \\
\text { Assistência Social (Suas). } \\
\text { IX Conferência Nacional de Assistência Social. }\end{array}$ \\
\hline 2 & \\
\hline
\end{tabular}

Fonte: Secretaria Nacional de Assistência Social/MDS. 
O Sistema Único de Assistência Social integra a rede pública e privada de serviços, programa, projetos e benefícios de assistência social que está organizada em dois tipos de proteção (BRASIL, 1993), conforme segue:

Proteção social básica: conjunto de serviços, programas, projetos e benefícios da assistência social que visa prevenir situações de vulnerabilidade e risco social por meio do desenvolvimento de potencialidades e aquisições e do fortalecimento de vínculos familiares e comunitários.

Proteção social especial: conjunto de serviços, programas e projetos que tem por objetivo contribuir para a reconstrução de vínculos familiares e comunitários, a defesa de direito, o fortalecimento das potencialidades e aquisições e a proteção de famílias e indivíduos para o enfrentamento das situações de violação de direitos.

A Constituição Federal de 1988, em seu artigo 204, definiu as competências dos entes federados na área da assistência social e atribuiu à esfera federal a coordenação e elaboração de normas gerais.

A despeito de a autonomia política e fiscal dos governos estaduais e municipais permitir que esses adotem uma agenda própria, independente da agenda do Executivo federal - ou seja, as garantias constitucionais do Estado federativo permitem que os governos locais estabeleçam sua própria agenda na área social (ARRETCHE, 2006) -, o papel de coordenação da União na implementação do Suas tem se dado com um razoável nível de adesão dos entes federados.

Nesse sentido, destacam-se dois pontos: a) o Suas está presente em quase todos os municípios brasileiros ${ }^{3}$; b) a União desempenha um importante papel de agenda settler no processo de pactuação federativa, como já foi observado em sua atuação na Comissão Intergestores Tripartite ${ }^{4}$, cujo percentual de aprovação das pactuações federativas é de mais de 80\% (PALOTTI; MACHADO, 2014).

\section{Financiamento federal no Suas}

A Norma Operacional Básica de 2005 (NOB/2005), que é fruto dos debates ocorridos na IV Conferência Nacional de Assistência Social, realizada em 2003, incorpora a preocupação sobre as finanças públicas na gestão da política de assistência social (CASTRO, 2012). Conforme explica Brandão (2012):

\footnotetext{
${ }^{3}$ Esse dado leva em consideração o fato de existir pelo menos um serviço do Suas com cofinanciamento federal em mais de $99 \%$ dos municípios brasileiros. Essa robusta adesão federativa advém da implantação dos Centros de Referência de Assistência Social (Cras), o qual representa um equipamento da Proteção Social Básica.

${ }^{4}$ A Comissão Intergestores Tripartite, criada pela Resolução no 130/2005 do Conselho Nacional de Assistência Social, trata-se de um espaço de pactuação federativa do Suas que conta com representações de gestores dos três entes federados (União, estados e municípios), caracteriza-se como instância de negociação e pactuação quanto aos aspectos operacionais da gestão do Sistema Descentralizado e Participativo da Assistência Social.
} 
Juntamente com a NOB/2005, a Política Nacional de Assistência Social de 2004 objetivou, no campo do financiamento, enfrentar, pelo menos, três grandes desafios: a) agrupar todos os recursos dos orçamentos públicos destinados à Assistência Social em unidades orçamentárias específicas, nos três níveis de governo; b) estruturar e dar capacidade de gestão aos Fundos de Assistência Social para que possam garantir financiamento de forma continuada aos serviços, programas, benefícios e ações de assistência social, assim, eliminando de vez a descontinuidade e a ineficácia no gasto público; c) consolidar, mediante incentivos financeiros, a estruturação de serviços e programas em consonância com os princípios e diretrizes da LOAS, afastando as práticas assistencialistas e clientelistas. (BRANDÃo, 2012, p. 9).

Além de criar uma arquitetura sistêmica que reorganizou a relação da União com os demais entes federados por meio de mecanismos de fortalecimento de gestão, da transparência e de pactuação federativa, a regulação do mecanismo de repasse de recursos contínuos e regulares, conforme disposto no artigo 30 da Lei Orgânica de Assistência Social, com o incentivo e a instituição dos fundos de assistência social, foi um importante marco para o avanço do financiamento público da política de assistência social.

Como argumentos para defesa do avanço do modelo de financiamento via repasse fundo a fundo, destacam-se a melhoria no fluxo financeiro, pois, diferentemente da lógica de financiamento via convênio, os repasses continuados contribuem para a estruturação de serviços contínuos (BRANDÃo, 2012), e a produção de um conhecimento sobre finanças públicas e da transformação do orçamento municipal em um mecanismo de consolidação da lógica do direito no âmbito da assistência social, algo que não poderia ocorrer na lógica de repasse via convênio (CASTRO, 2012).

A partir das autoras citadas acima, nota-se que a avaliação do aperfeiçoamento do modelo de financiamento no âmbito do Suas destaca uma evolução de uma lógica de financiamento via convênios para uma lógica de repasse fundo a fundo. Essa avaliação nos deu a dimensão, sob a ótica dos autores estudados, de que a utilização de convênios como mecanismo para financiamento dos serviços do Suas não permite uma organização adequada do orçamento por não possuir a previsibilidade e regularidade dos recursos repassados pelo modelo fundo a fundo.

A participação do orçamento da assistência social no orçamento da União sofreu um incremento considerável ${ }^{5}$ entre os anos de 2002 e 2012. E o repasse de recursos

\footnotetext{
5 Nos últimos dez anos, os valores investidos pela União na assistência social apresentaram um aumento considerável. Em valores constantes (corrigidos pelo IPCA/IBGE na data base de 31/12/2012), o total executado na Função 08 passou de R\$ 11,5 bilhões, em 2002, para R\$ 56,6 bilhões, em 2012, o que corresponde a um crescimento real de $392,8 \%$. Ao excluirmos as ações de transferência de renda - Programa Bolsa Família e o Benefício de Prestação Continuada -, a evolução do orçamento da assistência social passou de R\$ 1,7 bilhão em 2002 para R\$ 5,8 bilhões em 2012, equivalente a 246,2\% de aumento real (BRASIL, 2013). Já no período de 2012 a 2014, o valor pago para os serviços de Proteção Social Especial passou de R\$ 463,9 milhões para R\$ 599 milhões (não consideramos o valor executado em 2015, pois até abril de 2016 havia sido pago apenas $60 \%$ do valor empenhado no exercício de 2015).
} 
da União aos demais entes federados, por meio de repasses do Fundo Nacional de Assistência Social aos fundos estaduais e municipais de assistência social, significou a implantação e consolidação do Suas (BRASIL, 2013a).

Nesse sentido, a forma de transferência de recursos via convênio, no âmbito do Suas, ficou circunscrita às despesas de caráter não continuado (BRASIL, 2013a), tais como a destinação de recursos para a construção de unidades ofertantes de serviços ou para os municípios contemplados com emendas parlamentares ao orçamento.

\section{Orçamento impositivo no Suas}

Conforme dito anteriormente, alguns autores correlacionam a estruturação do Suas com a adoção de um modelo de financiamento via fundos de assistência social e uma consequente avaliação negativa do financiamento via convênio (relacionado à ineficácia e descontinuidade do gasto público). No entanto, esse modelo ainda perdura e agora assume um novo caráter em função do disposto pela Emenda Constitucional no 86/2015.

De acordo com a EC no 86/2015, ficou estabelecido um limite de 1,2\% da receita corrente líquida prevista no projeto de Lei Orçamentária Anual, encaminhado pelo Poder Executivo, para a realização de emendas parlamentares individuais, e se tornou obrigatória a execução orçamentária e financeira das programações criadas pelas emendas individuais a um montante correspondente a $1,2 \%$ da receita corrente líquida realizada no exercício anterior ${ }^{6}$.

A instituição do orçamento impositivo, em sua proposta original (PEC no 22 de 2000), pretendia abranger toda a programação da lei orçamentária, contudo "a aplicação das regras do orçamento impositivo apenas às programações objeto das emendas individuais decorreu da resistência política do Poder Executivo contra um modelo que expandia a obrigatoriedade de execução para toda a peça orçamentária" (GREGGIANIN; SILVA, 2015, p. 4).

Há um conjunto de argumentos contra e a favor da impositividade da execução do orçamento, assim como há posições que apoiam e não apoiam a criação do orçamento impositivo apenas às programações objeto de emendas individuais. Nosso objetivo não é discutir o mérito da inovação trazida pela EC no 86/2015, mas entender quais os novos cenários colocados para a gestão da política de assistência social diante dessa realidade.

Alguns autores destacam a importância de se pensar em mecanismos que aumentem a coordenação e planejamento sobre a alocação dos recursos públicos

\footnotetext{
${ }^{6}$ Esta Emenda Constitucional ganhou a alcunha de orçamento impositivo à brasileira (SCAFF, 2015).
} 
advindos de emendas parlamentares (RENNó JUNIOR; PEREIRA FILHO, 2013). Segundo esses autores, transferências de recursos via emendas individuais e coletivas podem ser de suma importância em situações onde recursos não chegariam por outras vias, assim como esses recursos podem conter um caráter dissipativo ${ }^{7}$.

Os referidos autores buscam comprovar que há efeitos positivos das emendas parlamentares sobre o desenvolvimento dos municípios brasileiros, contudo eles apontam duas características do processo de emenda ao orçamento que podem contribuir para a dissipação dos benefícios, tais como: a) caráter descentralizado da autoria e baixa coordenação entre as iniciativas de emendas orçamentárias propostas pelos parlamentares; b) grande volume de emendas aprovadas anualmente, na casa dos milhares, o que dificulta a discussão do mérito das emendas (RENNó JUNIOR; PEREIRA FILHO, 2013).

\section{Metodologia}

No presente estudo, trabalhamos com o impacto das emendas parlamentares ao orçamento da proteção social especial. A opção pelo recorte se deu por três motivos: a) no período de 2012 a 2015, houve um intenso processo de regulação e início do cofinanciamento federal para um grande número dos serviços desse nível de proteção; b) um conjunto significativo dos serviços de proteção social especial já existia antes da criação do Suas (acolhimento para idosos, crianças, adolescentes, mulheres e pessoas com deficiência; medidas socioeducativas em meio aberto para adolescentes infratores; habilitação e reabilitação de pessoas com deficiência, entre outros), o que significa que há um processo de adequação desse conjunto de serviços aos novos regulamentos, chamado de reordenamento; e c) um dos autores deste artigo trabalhou por três anos no Departamento de Proteção Social Especial da Secretaria Nacional de Assistência Social e, por dois anos, coordenou a análise de mérito das propostas de convênios decorrentes de emendas parlamentares.

Atualmente, há três ações orçamentárias no âmbito do orçamento da União que financiam os serviços de proteção social especial, que são as seguintes ${ }^{8}$ : a) Ação 2A65, em que se localizam os recursos destinados ao repasse fundo a

\footnotetext{
${ }^{7}$ Segundo Rennó Júnior e Pereira Filho, as políticas locais podem gerar alguma inclusão, mas também podem gerar dissipação de recursos ao particularizarem os benefícios e coletivizarem os custos. Na verdade, o atributo dissipativo pode ocorrer em qualquer política que não seja universalista e que seja, portanto, direcionada a públicos específicos. Para nosso estudo tentaremos apontar quais contextos podem ser mais propícios para ocorrência desse tipo de situação, tal como a destinação de recursos para municípios que não possuam serviços de Proteção Social Especial registrados nos sistemas de monitoramento do Ministério do Desenvolvimento Social e Combate à Fome.

${ }^{8}$ Essas ações orçamentárias fizeram parte do Programa 2037- Fortalecendo o Suas, do PPA 2012-2015.
} 
fundo ${ }^{9}$ para os serviços de proteção social especial de média complexidade (Serviço de Proteção e Atenção Especializada a Famílias e Indivíduos/Creas; Serviço Especializado para Pessoas em Situação de Rua/Centro POP; Serviço Especializado para Pessoas com Deficiência, Idosas e suas Famílias/Centro Dia; Serviço Especializado de Abordagem Social; e Serviço de Medidas Socioeducativas em Meio Aberto); b) Ação 2A69, na qual se localizam os recursos destinados ao repasse fundo a fundo para os serviços de proteção social especial de alta complexidade (serviços de acolhimento/abrigo para adultos, famílias, mulheres vítimas de violência, idosos, vítimas de calamidades, e crianças e adolescentes); c) Ação 2B31, pela qual são viabilizados os recursos destinados à estruturação da rede de proteção social especial, cujo repasse tem se dado via convênio ou contrato de repasse ${ }^{10}$.

Apesar de as ações orçamentárias 2A65 e 2A69 terem recebido dotações decorrentes de emendas parlamentares nos anos de 2012 e 2013, essas emendas ou foram da Comissão de Seguridade Social e Família ou foram do Relator Geral do orçamento. A Ação Orçamentária 2B31 é a que tem, historicamente, recebido dotações decorrentes de emendas parlamentares, mais precisamente das emendas parlamentares individuais.

Dessa forma, nosso foco de estudo foram as emendas parlamentares individuais para a Ação Orçamentária 2B31, pois essas emendas têm propiciado a realização de convênios e contratos de repasse no âmbito da proteção social especial e, consequentemente, têm sido a ação orçamentária para a qual os parlamentares têm realizado emendas orçamentárias.

Para identificarmos o montante de recursos aportados pelas emendas parlamentares ao orçamento da política de assistência social, levantamos, por meio do Siga Brasil ${ }^{11}$, os valores referentes à dotação orçamentária autorizada, valores empenhados, liquidados e pagos, bem como os restos a pagar pagos e não pagos.

\footnotetext{
${ }^{9}$ As transferências fundo a fundo representam um instrumento de descentralização de recursos disciplinado em leis específicas, que se caracterizam pelo repasse direto de recursos provenientes de fundos da esfera federal para fundos da esfera estadual, municipal e do Distrito Federal, dispensando a celebração de convênios. Os fundos que atualmente operam essa modalidade de transferência são o Fundo Nacional da Assistência Social (FNAS) e o Fundo Nacional de Saúde - FNS (Gomes, 2013, p. 3).

${ }^{10}$ Nos termos do art. 25 da Lei de Responsabilidade Fiscal, entende-se por transferências voluntárias a entrega de recursos correntes ou de capital a outro ente da Federação a título de cooperação, auxílio ou assistência financeira, que não decorra de determinação constitucional, legal ou os destinados ao Sistema Único de Saúde. Tais transferências são destinadas a atender a ações com propósitos específicos e com regras definidas caso a caso. São efetivadas por meio da celebração de Convênios ou Contratos de Repasse (LRF, p. 4).

${ }^{11}$ Siga Brasil é um sistema de informações sobre o orçamento público do Senado Federal que permite acesso amplo e facilitado ao Sistema Integrado de Administração Financeira (Siafi). O Siafi consiste no principal instrumento utilizado para registro, acompanhamento e controle da execução orçamentária, financeira e patrimonial do Governo Federal. Eis o link para acessar o Siga Brasil: <http://www12.senado.gov.br/orcamento/sigabrasil>
} 
Utilizamos dois universos distintos disponíveis na referida plataforma, quais sejam: "Elaboração Parecer Emenda" e "LOA - Despesa Execução". O primeiro nos permitiu consultar as dotações consignadas às Leis Orçamentárias Anuais provenientes de emendas parlamentares, oferecendo informações sobre o tipo de autor das emendas, natureza da despesa e valores dos autógrafos, entre outras. Já o segundo trouxe à luz informações concernentes à efetiva execução orçamentária, financeira e de restos a pagar das emendas parlamentares suportadas nas ações orçamentárias selecionadas.

Sobre o método utilizado para apuração da execução orçamentária e financeira das emendas tratadas, um esclarecimento se faz necessário: cada empenho emitido no âmbito da política de assistência social, cujo crédito seja proveniente de uma emenda parlamentar, recebe um código, um identificador, que é escolhido de acordo com a estrutura de Plano Interno (PI) estabelecida pela setorial orçamentária do MDS. Graças a isso, foi possível isolar os empenhos emitidos em favor das emendas parlamentares, bem como sua posterior execução financeira, seja a partir de pagamentos efetuados no mesmo exercício de emissão do empenho, seja na forma de execução de restos a pagar.

Ao levantarmos a execução orçamentária e financeira de todas as ações orçamentárias da proteção social especial, excluindo-se a execução das emendas parlamentares, e ao levantarmos a execução orçamentária e financeira apenas das emendas parlamentares, foi possível identificar qual a relevância orçamentária e financeira das emendas parlamentares para o orçamento da proteção especial como um todo.

Dessa forma, dividimos o ciclo orçamentário em três etapas: dotação, execução orçamentária e execução financeira. Na primeira etapa, analisamos a dotação autorizada para as três ações orçamentárias, destacando quanto dessa dotação dizia respeito às emendas parlamentares individuais, buscando, dessa forma, identificar a relevância das emendas no orçamento da proteção social especial do Suas.

$\mathrm{Na}$ segunda etapa, analisamos a execução orçamentária a partir do total empenhado em cada ação orçamentária no período em análise e o total empenhado das dotações decorrentes de emendas individuais. Já na terceira etapa, levantamos os valores pagos nas referidas ações orçamentárias e identificamos quanto desse valor dizia respeito ao que foi empenhado do orçamento decorrente das emendas individuais, o que nos permitiu ter a dimensão da participação das emendas na execução financeira. 
Por meio dos registros administrativos do Fundo Nacional de Assistência Social ${ }^{12}$ (FNAS), obtivemos acesso ao conjunto de convênios e contratos de repasse decorrentes de emendas parlamentares no período em análise.

Nessa base de dados, há um conjunto de 501 propostas firmadas entre a União (MDS) e os entes federados no período de 2012 a 2015, no âmbito da proteção social especial. Com essa base de dados, pudemos levantar informações sobre os seguintes pontos: a) situação da proposta (se cancelada, concluída ou ainda em execução); b) natureza da despesa (custeio, investimento, ou custeio e investimento); c) distribuição dos convênios por porte municipal e região geográfica.

Finalizando o levantamento quantitativo, a partir dos registros administrativos do FNAS e da base de dados do Censo Suas dos anos de 2012 a 2015, identificamos quais dos municípios que foram contemplados com recursos via emenda parlamentar informaram possuir Centro de Referência Especializado de Assistência Social, que é o equipamento público de referência da Proteção Social Especial.

Complementando a análise quantitativa, entrevistamos gestores nacionais do Suas para obtermos a percepção desses atores sobre a importância das emendas parlamentares para as estratégias e para o orçamento do Suas.

Nessa etapa, de imersão qualitativa, entrevistamos três gestores da Secretaria Nacional de Assistência Social do Ministério do Desenvolvimento Social e Combate à Fome, a saber: i) gestor da Secretaria Nacional de Assistência Social; ii) gestor do Departamento de Proteção Social Especial; e iii) gestor da Coordenação-Geral de Contratos e Convênios do Fundo Nacional de Assistência Social.

As entrevistas foram gravadas e transcritas, de modo que foi possível a organização das informações e a identificação das ideias centrais dos referidos entrevistados sobre a relevância, importância e o papel das emendas parlamentares no orçamento do Suas, assim como sobre a percepção desses gestores acerca da relação entre o Poder Executivo e o Poder Legislativo, a partir da perspectiva das emendas parlamentares ao orçamento do Suas.

Os conteúdos das entrevistas foram organizados em uma matriz, na técnica de classificação denominada de condensação de significados, em que tomamos trechos das entrevistas como unidades de registro com significação para o objetivo analítico em questão (KVALE, 1996 apud BRITO, 2007). Em seguida, para cada unidade de registro foi realizada uma síntese e, ao final da matriz, registrada

\footnotetext{
${ }^{12}$ O FNAS é um fundo público de gestão orçamentária, financeira e contábil instituído pela Lei no 8742/93 e regulado pelo Decreto no 7788/2012, cujo objetivo é proporcionar recursos para cofinanciar gestão, serviços, programas, projetos e benefícios de assistência social.
} 
a interpretação de significados referente à categoria analisada (ARAúJo JR., 2000 apud BRITO, 2007).

A condensação de significados objetivou organizar e sumarizar os conteúdos das entrevistas para a apresentação de ideias-síntese quanto ao problema de pesquisa. A técnica permitiu uma abreviação dos significados encontrados no conteúdo dos registros, em formato condensado, porém sem perder a sua essência, o que possibilitou transformar longos trechos de texto em notas mais curtas (KVALE, 1996 apud BRITO, 2007).

Por sua vez, a interpretação de significados buscou o sentido mais amplo das ideias e temas suscitados, devido a sua ligação com conhecimentos previamente adquiridos e também permitiu construir relação entre as falas dos entrevistados e os dados levantados (ARAúJo JR., 2000 apud BrITO, 2007).

Abaixo segue matriz utilizada para a realização da condensação e interpretação de significados:

\section{Quadro 2 - Matriz de condensação e interpretação de significados}

\begin{tabular}{|c|c|}
\hline \multicolumn{2}{|l|}{ Fonte de dados: } \\
\hline \multicolumn{2}{|l|}{ Entrevista } \\
\hline \multicolumn{2}{|l|}{ Documento/Texto } \\
\hline \multicolumn{2}{|l|}{ Diário de campo } \\
\hline \multicolumn{2}{|l|}{ Objetivo/Categoria analítica relacionados: } \\
\hline Unidade de registro & Temas centrais \\
\hline Trechos do material de pesquisa (fala, registro de campo, documento) & $\begin{array}{l}\text { Análises do pesquisador sobre o trecho em questão (em um esforço } \\
\text { de síntese do conteúdo) }\end{array}$ \\
\hline \multicolumn{2}{|c|}{ Descrições essenciais para responder aos objetivos da pesquisa } \\
\hline \multicolumn{2}{|c|}{ Interpretação realizada pelo pesquisador acerca das questões suscitadas no trecho analisado } \\
\hline
\end{tabular}

Fonte: Brito (2007).

\section{Resultados}

A partir dos dados do Siga Brasil, verificamos que a dotação orçamentária para os serviços (ações orçamentárias 2 A69 e 2A65) da Proteção Social Especial (PSE) evoluiu, no período estudado, $20 \%$ em valores nominais e $4 \%$ em valores corrigidos. Em sentido oposto, os valores decorrentes de emendas ao orçamento da PSE (ação orçamentária 2B31) reduziram-se $105 \%$ em valores nominais e $144 \%$ em valores atualizados $^{13}$. Dessa forma, a participação das emendas individuais no orçamento da PSE passou de 9\% em 2012 para 4\% em 2015.

\footnotetext{
${ }^{13}$ Os valores foram corrigidos pelo Índice de Preço ao Consumidor Amplo (IPCA IBGE) com data-base de $31 / 12 / 2015$.
} 
Gráfico 1 - comparação entre dotação orçamentária para os serviços e dotação orçamentária advinda de emendas parlamentares

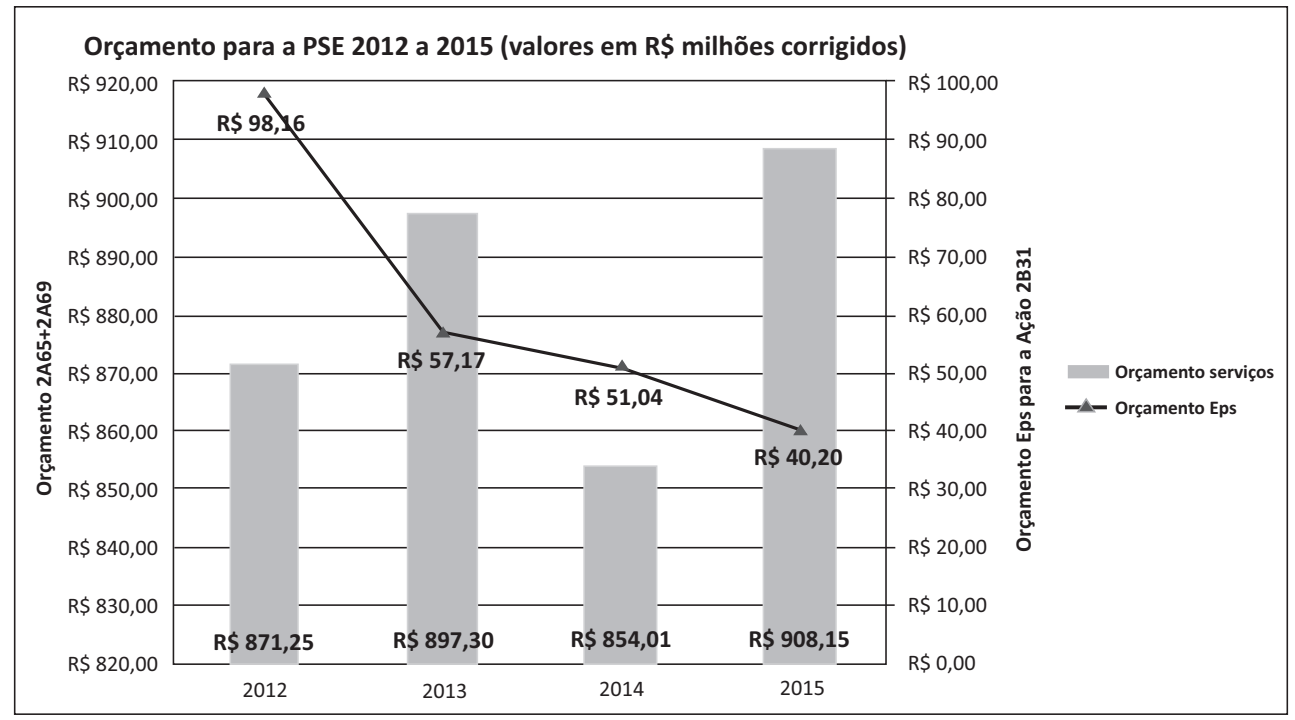

Fonte: Siga Brasil 2016.

Percebe-se, no período analisado, que o orçamento para repasse de recursos fundo a fundo (ações orçamentárias 2A69 e 2A65) cresceu e o valor das emendas individuais ao orçamento decresceu. Nesse sentido, podemos concluir que a participação das emendas individuais ao orçamento da PSE reduziu-se significativamente, tanto pelo fato de o valor alocado nas outras ações orçamentárias ter aumentado quanto pelo valor total das emendas ter diminuído, o que nos leva a concluir que, em um primeiro momento, o orçamento impositivo não significou incremento de dotação orçamentária advinda de emendas parlamentares ao orçamento do Suas.

Quando analisamos os valores empenhados, percebemos que as ações orçamentárias para serviços (2A65 e 2A69) possuem uma média, para o período, acima de $80 \%$ em valores empenhados (87,8\% para a Ação 2 A65 e 83,7\% para a Ação 2A69), enquanto a ação orçamentária para estruturação da rede (2B31) possui uma média de empenho de 52,3\%. No entanto, cabe destacar que a participação das emendas no total empenhado para a ação orçamentária 2B31 vem crescendo no período, de forma significativa. Enquanto em 2012 a participação foi de apenas 33,2\%, em 2015 essa participação saltou para 74\%.

Dessa forma, percebemos que a participação das emendas na execução orçamentária total da PSE também vem caindo. No ano de 2012 era de 6\% e no ano de 2015 foi de apenas 2\%. Essa diminuição possui a mesma lógica da dotação orçamentária, pois houve uma redução dos valores absolutos de emendas 
empenhadas (em linha com a diminuição dos valores da dotação orçamentária) e houve um aumento dos valores absolutos empenhados nas ações 2A65 e 2A69 (que condiz com o aumento da dotação dessas ações).

Gráfico 2 - Comparação entre execução orçamentária para os serviços e execução orçamentária advinda de emendas parlamentares

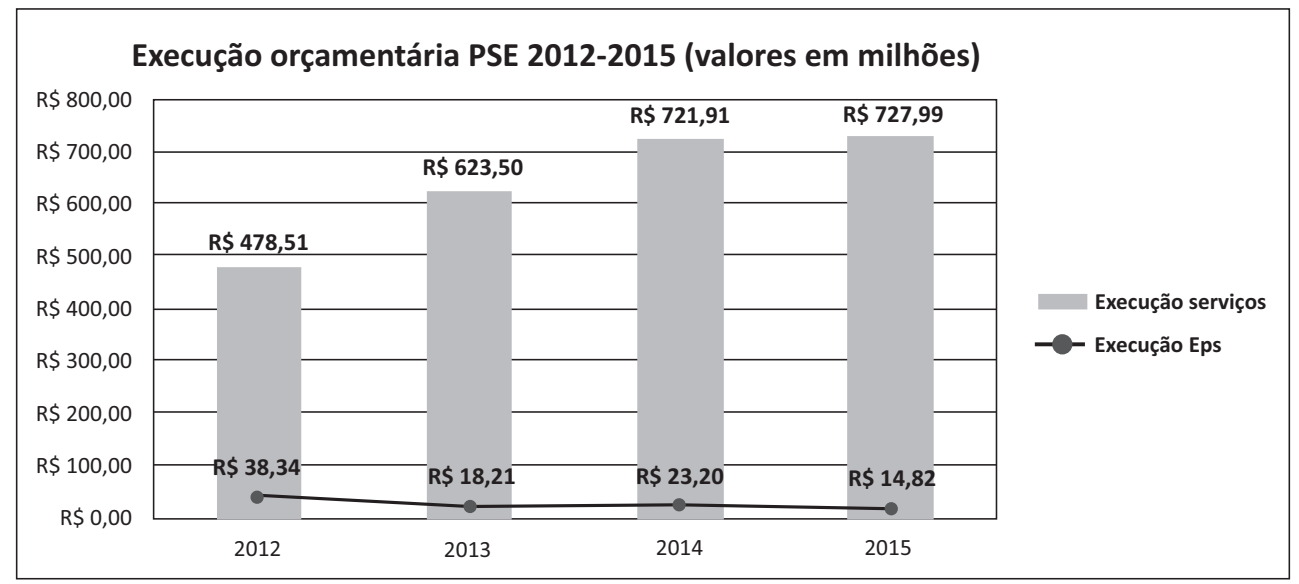

Fonte: Siga Brasil 2016.

No que diz respeito aos valores pagos em face dos valores empenhados, as ações orçamentárias referentes aos serviços tiveram, no período analisado, a maior parte de seus valores empenhados paga no respectivo exercício. O desempenho da execução financeira dessas ações está relacionado com a modalidade de aplicação adotada (Modalidade 31 - Transferências a Estados e ao Distrito Federal - Fundo a Fundo, e Modalidade 41 - Transferências a Municípios - Fundo a Fundo), pois essa modalidade permite uma transferência mais célere de recursos da União para os entes federados, reforçando a tese levantada por Castro (2012) de que o repasse fundo a fundo consolida a lógica do direito no âmbito da assistência social em função de previsibilidade e facilidade de execução.

Quanto à Ação 2B31, apenas no ano de 2014 houve pagamento no exercício de valor empenhado, ainda assim o percentual foi bastante baixo (14,9\% do valor empenhado foi pago). Nos demais anos, os valores pagos para a Ação 2 B31 dizem respeito a valores empenhados em anos anteriores.

Dessa forma, analisando a execução financeira da Ação 2B31, tomando o mês de abril de 2016 como referência, foi pago 77\% (39\% desse valor dizia respeito à emenda individual) do total empenhado no ano de 2012; 50\% (62\% desse valor dizia respeito à emenda individual) do total de $2013 ; 58 \%$ (80\% desse valor dizia respeito à emenda individual) do total de 2014; e 0\% do total empenhado em 2015. Percebe-se que o pagamento de emendas cresceu no período diante do total de 
pagamentos realizados na Ação 2B31. No ano de 2014, o pagamento das emendas correspondeu a $80 \%$ de todo valor pago nessa Ação.

Gráfico 3 - Participação das emendas parlamentares na execução financeira da Ação 2B31

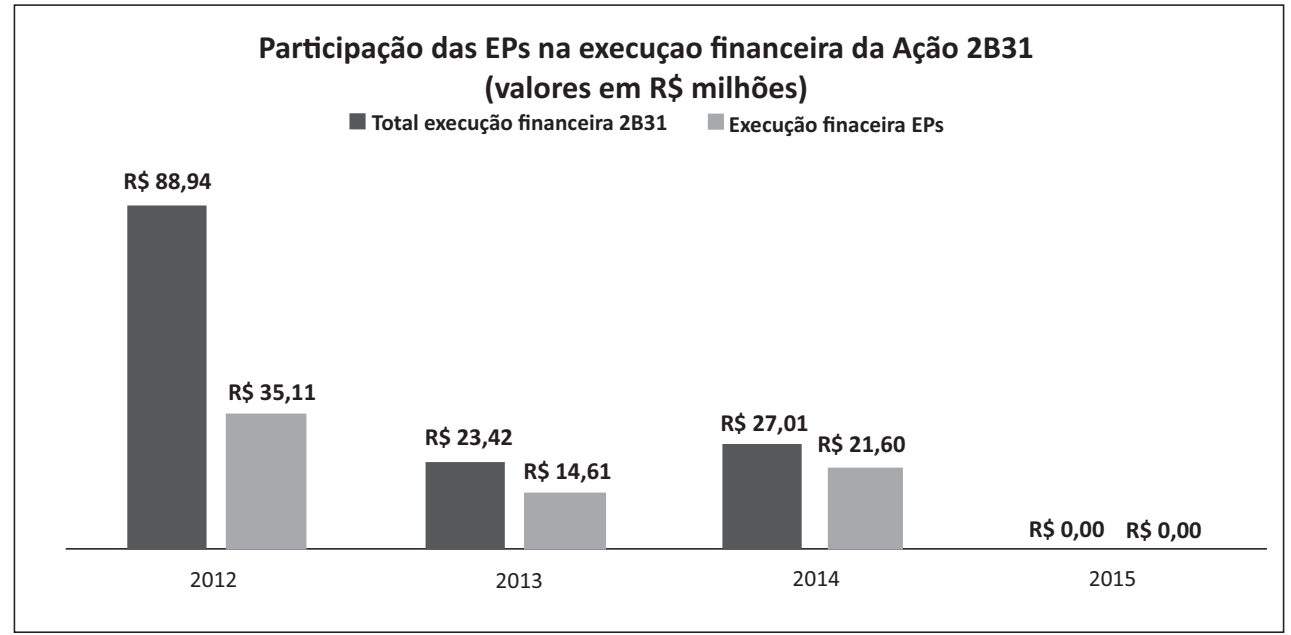

Fonte: Siga Brasil 2016.

Pode-se observar que a velocidade da execução financeira da Ação 2B31 é bastante distinta da execução das demais ações orçamentárias que suportam o cofinanciamento fundo a fundo, e que, em um primeiro momento, o orçamento impositivo não significou qualquer incremento na execução financeira dos recursos oriundos de emenda parlamentar.

De fato, o regramento que criou o orçamento impositivo determina prazos a serem cumpridos no que diz respeito às medidas a serem tomadas nos casos de impedimento técnico no empenho da despesa; já a execução financeira depende de outros fatores, tais como a existência de recurso em caixa na União e capacidade de execução do convênio por parte dos entes.

Em valores absolutos, a execução financeira das emendas caiu 38\% (45\% em valores corrigidos) entre os anos de 2012 e 2014 e a participação das emendas na execução financeira da PSE passou de 6\% em 2012 para 3\% em 2014. Contudo, podemos observar que, de 2013 a 2014, houve um aumento de 50\% na execução financeira das emendas. Os valores empenhados em 2015 ainda não foram pagos, mas certamente serão menores do que os de 2014, pois o valor empenhado nesse ano foi maior do que naquele.

A partir da realização das entrevistas com os gestores da Secretaria Nacional de Assistência Social, foi possível identificar 10 temas-chave que foram agrupados em três grandes categorias, conforme quadro abaixo: 
Quadro 3 - Categorias de análise e temas-chave relacionados

\begin{tabular}{|c|c|}
\hline Categorias & Temas-chave \\
\hline \multirow{3}{*}{ Organização administrativa } & Regulação das emendas impositivas no Suas \\
\hline & Estrutura da SNAS \\
\hline & Impacto da EC no 86/2015 \\
\hline \multirow{3}{*}{ Atores } & Emenda parlamentar e controle social \\
\hline & Relação Executivo-Legislativo \\
\hline & O papel da rede privada no Suas \\
\hline \multirow{4}{*}{ Financiamento da política } & $\begin{array}{l}\text { Predominância do modelo convenial e peso das } \\
\text { emendas no período pré-Suas }\end{array}$ \\
\hline & Novo modelo de financiamento \\
\hline & Destinação dos recursos das emendas \\
\hline & Relevância das emendas no contexto atual do Suas \\
\hline
\end{tabular}

Fonte: Elaborado pelos autores.

Ao interpretarmos as falas relacionadas à categoria Organização administrativa, há um reconhecimento de que as LDOs de 2014 e 2015 e a Emenda Constitucional no 86/2015 causaram impacto no processo de análise e formalização de convênios decorrentes de emendas parlamentares, principalmente com a definição mais clara de um calendário a ser cumprido pelos parlamentares, pelos gestores nacionais e pelos gestores locais. Essa melhor definição dos prazos e responsabilidades contribuiu para uma melhor organização das rotinas de trabalho.

Por outro lado, a gestão da SNAS apontou para algumas necessidades de melhorias na estrutura e nos processos de análise. Nesse ponto, as falas possuíam convergências, como na questão de uma maior integração entre a proteção social básica e a proteção social especial (fala dos entrevistados 01 e 03); e divergências, como quando tratam da estrutura existente para análise de convênios, pois um entrevistado falou da necessidade de se concentrarem as atividades em apenas um setor da SNAS e outro entrevistado elogiou a desconcentração das atividades 
relacionadas ao processo de análise, formalização e fiscalização dos convênios (entrevistados 01 e 02).

Levantou-se a questão de as emendas parlamentares poderem causar desequilíbrios na destinação de recursos federais, com alguns municípios recebendo mais e outros recebendo menos recursos. Essa preocupação possui pertinência, pois verificamos que $6 \%$ dos entes federados que firmaram convênio com a SNAS, entre os anos de 2012 e 2015, concentravam 19\% dos convênios. Também pudemos observar que a distribuição regional dos convênios tende a concentrar-se em algumas regiões específicas.

No período analisado, a distribuição regional dos convênios foi a seguinte:

\section{Gráfico 4 - Distribuição regional dos convênios}

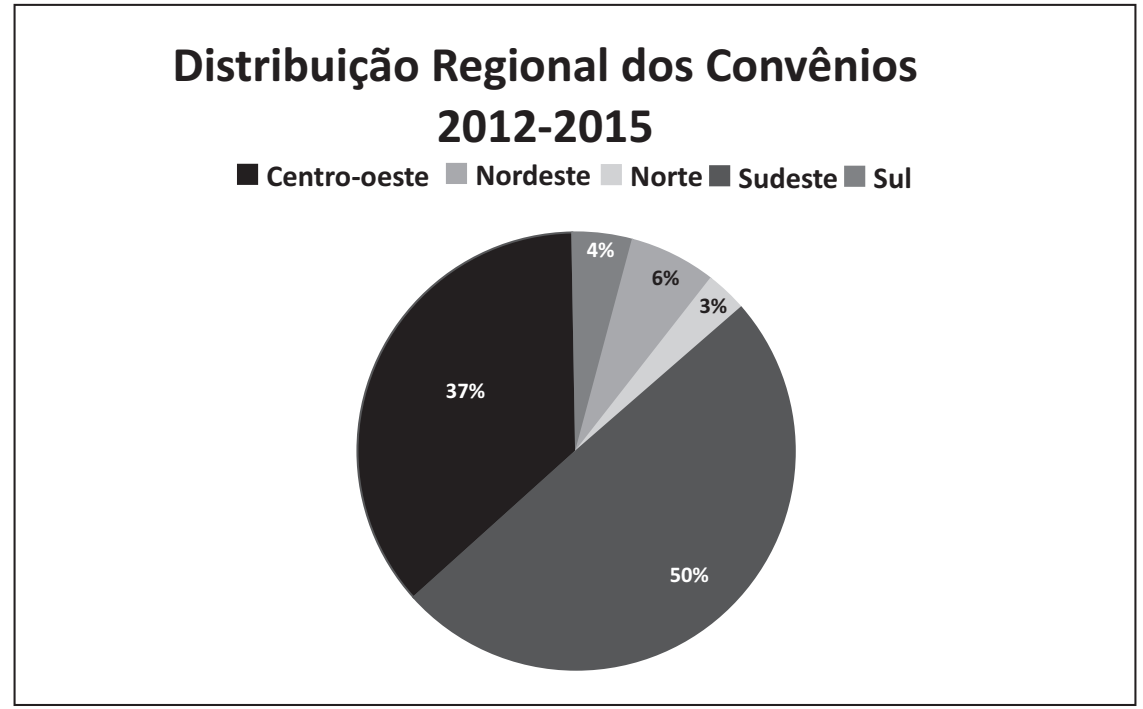

Fonte: Fundo Nacional de Assistência Social, 2015.

Os gestores entrevistados vislumbraram algumas ações que podem prevenir esse risco ou reduzir seu impacto. Nesse sentido, citou-se a experiência do Ministério da Saúde, como possibilidade de se induzir recursos via emenda para ações orçamentárias que suportam o cofinanciamento fundo a fundo dos serviços, assim como a necessidade de se lançar mão dos dados de monitoramento disponíveis para a estruturação de um cardápio de opções para os parlamentares. Esse tipo de iniciativa poderia ajudar a reduzir o risco do caráter dissipativo das emendas parlamentares.

Nesse sentido, destaca-se que, desde o ciclo orçamentário de 2014, as LDOs têm possibilitado, na seção que trata do orçamento da seguridade social, que o Ministério do Desenvolvimento Social e Combate à Fome e o Ministério da Saúde, independentemente da opção de custeio ou investimento, regulem as emendas 
parlamentares que adicionarem recursos a transferências automáticas e regulares a serem realizadas pela União a ente federado. Contudo, o MDS, ao contrário do Ministério da Saúde, não atentou para a regulamentação desses dispositivos presentes nas LDOs de 2014, 2015 e $2016^{14}$.

Quanto à categoria Atores, o Entrevistado 01 destacou o fato de o Suas ter priorizado, nos últimos dez anos, uma agenda mais interna, voltada para a regulação dos espaços de discussão, dos serviços, das profissões, e a realização de pactuações federativas entre os gestores da política de assistência social, e que a agenda futura deve estar mais atenta aos atores externos, entre eles o Poder Legislativo.

O processo de elaboração do orçamento, e mais especificamente a realização de emendas parlamentares ao orçamento da assistência social, foi apontado como um momento oportuno para construção de uma agenda comum entre os gestores da política de assistência social e o Parlamento.

No bojo dessa agenda a ser estabelecida com o Parlamento, percebeu-se que há interesse, por parte dos gestores entrevistados, de se fomentar a estruturação da rede de serviços socioassistenciais com o incentivo à realização de emendas parlamentares que disponibilizem recursos de capital para construção e compra de equipamento e material permanente, assim como há uma preocupação em apresentar o Suas para os parlamentares, fundada em duas percepções: a) possível desconhecimento da rede socioassistencial e de suas demandas pelos parlamentares; b) e a existência de uma concepção atrasada de assistência social, em parte dos integrantes do Parlamento.

Percebeu-se, na fala dos demais entrevistados, que há uma necessidade de se aprofundar o diálogo com o Poder Legislativo, com vistas a alinhar as emendas ao orçamento nacional do Suas com os objetivos da política de assistência social.

Pela fala dos entrevistados, há uma percepção de que a rede privada permanece como um destinatário preferencial das emendas parlamentares. Se, antes do orçamento impositivo, o Poder Executivo manejava com maior tranquilidade os recursos das emendas, liberando-os para a rede privada de acordo com a conveniência e a oportunidade, agora, com a execução obrigatória, a gestão do Suas reconheceu a necessidade de se aprofundar o diálogo sobre a destinação de

\footnotetext{
${ }^{14} \mathrm{Em}$ consulta à Subsecretaria de Planejamento e Orçamento do Ministério do Desenvolvimento Social e Combate à Fome sobre o porquê de o órgão não ter regulado o §9o do art. 36 da LDO 2014 (Lei no 12.919/2013), o §6ㅇdo art. 36 da LDO 2015 (Lei no 13.080/2015) e o §6ㅇ do art. 38 da LDO 2016 (Lei no 13.242/2015), fomos informados que "não ocorreram emendas parlamentares individuais nas transferências automáticas e regulares do MDS, que seriam emendas nas ações de serviços do FNAS. As emendas do FNAS foram todas para obras e material permanente como veículos e obras [...] Como não ocorreram emendas desse tipo no MDS, não há o que normatizar até o momento". Essa resposta demonstrou o desconhecimento por parte do órgão do que dispunha os normativos citados e da própria natureza dos recursos oriundos de emendas, que não são somente para investimento.
} 
recursos via emenda parlamentar. Os dados disponíveis na base de dados do FNAS sobre convênios firmados não nos permitiram identificar o montante de convênios que contempla a rede pública e o montante que contempla a rede privada.

Ainda tratando dos atores relacionados à questão das emendas, um dos entrevistados levantou a importância de se verificar como tem se dado a atuação dos conselhos municipais na aprovação dos recursos destinados via emenda parlamentar.

Esse tema, apesar de não fazer parte do estudo em questão, é um importante recorte, a ser considerado em estudos futuros, do processo de destinação de recursos federais via emenda parlamentar, pois os conselhos locais de assistência social cumprem um importante papel, que vai desde a certificação das entidades privadas que fazem parte da rede socioassistencial do município, até a discussão da destinação de recursos federais para essas entidades.

Nas falas relacionadas à categoria Financiamento da política de assistência social, foi evidenciado que, no período anterior à regulação do Suas, o orçamento para a assistência social era bastante dependente de emendas parlamentares e boa parte desse recurso era destinado para as entidades privadas que historicamente ofertavam serviços de assistência social (entidades filantrópicas que desde muito tempo ofertam serviços de acolhimento a crianças, idosos, pessoas em situação de rua, realizam trabalho social com pessoas com deficiência, idosas e suas famílias).

Após o início da estruturação do Suas, com o investimento federal na implantação de unidades públicas estatais (rede de Cras e Creas) e com a regulação dos serviços socioassistenciais (Resolução CNAS no 109/2009), as emendas parlamentares também passaram a ser destinadas para essa rede pública. Nesse sentido, o que se percebe na fala dos gestores nacionais é que as emendas parlamentares têm suprido alguns pontos não cobertos pelo cofinanciamento federal realizado pelo repasse fundo a fundo, principalmente no que diz respeito à destinação de recursos para construção e aquisição de equipamento e material permanente (despesas de capital) para a rede pública ou a suplementação de recursos em períodos específicos.

Nesse ponto, observamos que se evidencia um debate importante sobre o uso do fundo público na política de assistência social, forjado pela mudança de orientação da política nos últimos anos, que sai da primazia da oferta no âmbito da esfera privada de serviços públicos para uma centralidade do Estado na oferta de serviços de assistência social. Sob essa perspectiva, percebe-se um consenso entre os entrevistados com a visão de que não deve haver uma competição entre uma oferta estatal e uma oferta pela sociedade civil, mas sim a necessidade de aproveitar a expertise e abrangência dessa rede histórica para uma ampliação da proteção social. 


\section{Conclusão}

Nosso trabalho visou a uma primeira aproximação do tema no âmbito da política nacional de assistência social e, nesse sentido, conseguimos identificar um conjunto de questões relacionadas ao aperfeiçoamento administrativo e ao aprofundamento da relação entre o Executivo e o Legislativo, assim como pudemos ter a dimensão do papel das emendas parlamentares no orçamento da Proteção Social Especial no Suas no período analisado.

No que diz respeito ao aperfeiçoamento administrativo, observamos que a gestão nacional do Suas reconhece a importância de se melhorar os mecanismos de orientação e indução de emendas ao orçamento da assistência social.

Nesse aspecto, destacam-se: a) a necessidade de se regular ${ }^{15}$ artigo da LDO que trata da possibilidade de se realizar emenda parlamentar nas ações orçamentárias que suportam o repasse fundo a fundo; b) incorporação do calendário de discussão do orçamento no processo de monitoramento realizado pela SNAS $\left.{ }^{16} ; c\right)$ estruturação de uma base de dados a ser consultada pelos parlamentares antes de realizarem emendas ao orçamento com informações sobre as demandas distribuídas por entes e itens de despesa; d) e um maior envolvimento da alta administração do Suas nessa agenda.

Há um reconhecimento, por parte dos gestores entrevistados, da necessidade de se fortalecer a agenda entre a gestão do Suas e o Parlamento, e o processo de elaboração do orçamento é tido como um momento adequado, principalmente no atual contexto da EC no 86/2015.

Contudo, pudemos observar que a gestão do Suas, mesmo com o orçamento impositivo vigendo nas LDOs de 2014 e 2015 e vigendo na LOA de 2016 por meio da EC no 86/2015, ainda não incorporou em sua agenda a necessidade de diálogo com o Poder Legislativo no que diz respeito ao processo orçamentário.

Percebemos, inclusive, na fala de um dos gestores entrevistados, uma percepção equivocada a respeito da discricionariedade que possuiu o Poder Executivo até o orçamento de 2013 para a execução das emendas individuais. 0 montante elevado de convênios para despesas de investimento decorre muito menos de um possível pacto entre os Poderes Legislativo e Executivo, do que da

\footnotetext{
${ }^{15}$ Ministério da Saúde já vem realizando esse processo há dois ciclos orçamentários, vide Portarias no 600/2015 e no 268/2016 do Ministério da Saúde.

${ }^{16}$ No ano de 2015, no período em que os parlamentares estavam definindo as emendas ao orçamento de 2016, foi realizada uma primeira apresentação das demandas da rede de serviços do Suas, contudo essa iniciativa foi bastante tímida (apenas 1 encontro com os assessores parlamentares) e careceu de maior envolvimento da alta administração.
} 
liberdade que possuiu o Executivo para a execução de emendas que destinavam recursos de capital para os entes ${ }^{17}$.

No que diz respeito ao financiamento via emendas parlamentares, ficou clara uma percepção convergente entre os gestores entrevistados no sentido de que boa parte das emendas parlamentares são destinadas a entidades privadas, e que se faz necessário um acompanhamento dessa rede privada, no sentido de se ampliar a proteção social por meio da integração entre as ofertas de serviços por meio da rede pública e privada de assistência social.

Contudo, a base de dados disponível no Fundo Nacional de Assistência Social não disponibiliza a informação sobre o beneficiário final do recurso, o que nos impossibilitou avaliar se a percepção dos entrevistados condiz com a realidade. Nesse sentido, será oportuno que o MDS insira em sua base de dados de gestão dos convênios uma variável que possibilite a identificação do beneficiário final da emenda, pois essa é uma informação-chave para a gestão da política de assistência social.

A participação das emendas no orçamento da Proteção Social Especial vem caindo no período. Em parte, essa queda se explica pelo fato de o orçamento das ações que sustentam o repasse fundo a fundo ter aumentado; contudo, em valores absolutos, essa participação também vem caindo. É preciso haver uma série histórica mais longa para que possamos fazer uma avaliação mais precisa do real impacto do orçamento impositivo nesse aspecto.

Podemos concluir que, entre os efeitos colaterais, desejados ou não, da criação do orçamento impositivo, a gestão nacional da política de assistência social reconhece a necessidade de se estreitar o diálogo com o Poder Legislativo no que diz respeito ao processo orçamentário e à implementação do Suas. Dessa forma, com os achados deste artigo, espera-se poder apresentar informações e análises que subsidiem, a partir da perspectiva do orçamento impositivo, a construção de uma agenda com o Parlamento brasileiro para o fortalecimento da política de assistência social.

\footnotetext{
${ }^{17}$ No período analisado, $69,5 \%$ dos convênios firmados foram para investimento; $25,1 \%$ foram destinados ao custeio de serviços; e 5,4\% foram destinados para as duas naturezas de despesa, segundo dados do Fundo Nacional de Assistência Social.
} 


\section{Referências bibliográficas}

ARRETCHE, M. Federalismo e políticas sociais no Brasil: problemas de coordenação e autonomia. In: Saraiva, E.; Ferrarezı, E. (Orgs.) Políticas Públicas: coletânea. v. 2. Brasília: Enap, 2006. p.91-110.

BOSCHETTI, I.; TEIXEIRA, S. O. Imprecisão conceitual e pulverização dos recursos federais na função assistência social. Revista Ser Social, Brasília, p. 115-144, 2002.

BRANDÃo, F. A. O financiamento público da assistência social. Brasília - DF, 2012.

BRASIL. Decreto $n^{\circ} 7.788$, de 15 de agosto de 2012. Regulamenta o Fundo Nacional de Assistência Social, instituído pela Lei no 8.742, de 7 de dezembro de 1993, e dá outras providências. Disponível em: <http://www.planalto.gov.br/ccivil_03/_ Ato2011-2014/2012/Decreto/D7788.htm>. Acesso em: 15 de dezembro de 2015.

BRASIL. Lei n 8.742, de 7 de dezembro de 1993. Dispõe sobre a organização da assistência social e dá outras providências. Disponível em: <http://www.planalto. gov.br/ccivil_03/Leis/L8742.htm>. Acesso em: 27 de março de 2016

BRASIL. Ministério do Desenvolvimento Social e Combate à Fome. Caderno Suas VI: financiamento da assistência social no Brasil. Brasília - DF, 2013a.

BRASIL. Ministério do Planejamento, Orçamento e Gestão. Secretaria de Orçamento Federal. Manual técnico de orçamento MTO. Edição 2014. Brasília, 2013b.

Brito, R. L. Análise da Política de Descentralização das Ações de Vigilância Sanitária no Brasil: do debate sobre o repasse de recursos ao compromisso com a responsabilidade sanitária. 2007. 205 f. Dissertação (Mestrado em Ciências). Centro de Pesquisas Aggeu Magalhães, Fundação Oswaldo Cruz, Recife, 2007.

CAStRo, M. I. N. de. Pacto Federativo e financiamento da assistência social: as implicações da regulação do Suas sobre os orçamentos municipais. Revista Temporalis, p. 69-96. Brasília, 2012.

Greggianin, Eugênio; Silva, José de Ribamar Pereira da. Estudo Técnico Conjunto no 1, de 2015: o regime do orçamento impositivo das emendas individuais disposições da Emenda Constitucional no 86, de 2015, e da LDO de 2015. Congresso Nacional: 2015.

GoMES, Luciano de Souza. Repasse de recursos: convênio ou transferência fundo a fundo? Orçamento Público em Questão. Senado Federal: 2013.

PALOTTI, P. L. M.; MACHADO, J. A. Coordenação federativa e a "armadilha da decisão conjunta": As Comissões de Articulação Intergovernamental das Políticas Sociais no Brasil. DADOS - Revista de Ciências Sociais, p. 399-441. Rio de Janeiro, 2014.

Rennó, L. R. J.; PereiRA, C. E. F. F. Gastos públicos, emendas orçamentárias do Legislativo e inclusão dissipativa nos municípios brasileiros: 1998 a 2010. Universidade de Brasília - UNB, 2013.

SCAFF, F. F. Surge o orçamento impositivo à brasileira pela Emenda Constitucional no 86. Disponível em: <http://www.conjur.com.br/2015-mar-24/contas-vista-surgeorcamento-impositivo-brasileira-ec-86> Acesso em: 22 de novembro de 2015. 


\section{Rodrigo Morais Lima Delgado}

Especialista em Gestão Pública pela Escola Nacional de Administração Pública (Enap) e Analista Técnico de Políticas Sociais no âmbito do Poder Executivo Federal. Contato: rodelgado80@gmail.com

\section{Rodrigo Lino de Brito}

Possui mestrado em Saúde Pública pelo Centro de Pesquisa Aggeu Magalhães da Fundação Oswaldo Cruz (Fiocruz). Integra a carreira de Especialista em Políticas Públicas e Gestão Governamental (EPPGG). Contato: rodrigo.lino.brito@gmail.com

\section{Mariana Helcias Côrtes Sagastume}

Possui mestrado em Nutrição Humana pela Universidade de Brasília (UnB). Atualmente é Assessora no Gabinete da Secretaria-Executiva do Ministério do Desenvolvimento Social. Contato: marianahelcias@gmail.com

\section{Bruno Pinto Moraes}

Possui graduação em Ciências Econômicas pela Universidade de Brasília (UnB). Tem experiência na área de Economia, com ênfase em Economia Monetária e Fiscal. Atualmente é servidor do Tribunal de Contas da União. Contato: brunomoraesbsb@gmail.com 
RSP 